\title{
Image-guided intrathecal baclofen pump catheter implantation: a technical note and case series
}

\author{
Shenandoah Robinson, MD, ${ }^{1,2}$ Faith C. Robertson, BS, ${ }^{2}$ Hormuzdiyar H. Dasenbrock, MD, ${ }^{2,3}$ \\ Cormac P. O'Brien, ${ }^{4}$ Charles Berde, MD, PhD, ${ }^{5}$ and Horacio Padua, MD $^{6}$
}

Departments of ${ }^{1}$ Neurosurgery, ${ }^{5}$ Anesthesia, and ${ }^{6}$ Radiology, Boston Children's Hospital; ${ }^{2}$ Harvard Medical School; ${ }^{3}$ Department of Neurosurgery, Brigham and Women's Hospital, Boston, Massachusetts; and Royal College of Surgeons in Ireland, Dublin, Ireland

OBJECTIVE Medically refractory spasticity and dystonia are often alleviated with intrathecal baclofen (ITB) administration through an indwelling catheter inserted in the lumbar spine. In patients with cerebral palsy, however, there is a high incidence of concomitant neuromuscular scoliosis. ITB placement may be technically challenging in those who have severe spinal deformity or who have undergone prior instrumented thoracolumbar fusion. Although prior reports have described drilling through the lumbar fusion mass with a high-speed bur, as well as IT catheter implantation at the foramen magnum or cervical spine, these approaches have notable limitations. To the authors' knowledge, this is the first report of ITB placement using cone beam CT (CBCT) image guidance to facilitate percutaneous IT catheterization.

METHODS Data were prospectively collected on patients treated between November 2012 and June 2014. In the interventional radiology suite, general anesthesia was induced and the patient was positioned prone. Imaging was performed to identify the optimal trajectory. Percutaneous puncture was performed at an entry site with image-guided placement of a sheathed needle. CBCT provided real-time 2D projections and 3D reconstructions for detailed volumetric imaging. A biopsy drill was passed through the sheath, and subsequently a Tuohy needle was advanced intrathecally. The catheter was threaded cephalad under fluoroscopic visualization. After tip localization and CSF flow were confirmed, the stylet was replaced, the external catheter tubing was wrapped sterilely in a dressing, and the patient was transported to the operating room. After lateral decubitus positioning of the patient, the IT catheter was exposed and connected to the distal abdominal tubing with typical pump placement.

RESULTS Of 15 patients with Gross Motor Function Classification System Levels IV and V cerebral palsy and instrumented thoracolumbar fusion, 8 had predominantly spasticity, and 7 had mixed spasticity and dystonia. The mean age of patients was 20.1 years (range 13-27 years). Nine patients underwent initial catheter and pump placement, and 6 underwent catheter replacement. The procedure was technically successful, with accurate spinal catheter placement in all patients. The median hospital stay was 4 days (IQR $3-5$ days). One patient had an early postoperative urinary tract infection. With a mean follow-up of 25.8 months (median 26, range 18-38 months), no CSF leakage or catheter failure occurred. One late infection due to Pseudomonas aeruginosa (requiring pump explantation) occurred at 4 months, probably secondary to recurrent urinary tract infections.

CONCLUSIONS Image-guided CBCT navigation resulted in accurate percutaneous placement of the IT catheter for ITB pumps in patients with prior instrumented thoracolumbar fusion. The multimodality approach is an alternate technique that may be used for IT catheter insertion in patients with complex lumbar spine anatomy, extending the potential to provide safe, durable ITB therapy in this population.

https://thejns.org/doi/abs/10.3171/2016.8.SPINE16263

KEY WORDS cerebral palsy; cone beam computed tomography; dystonia; image guidance; minimally invasive; scoliosis; spasticity; thoracolumbar fusion; surgical technique 
$\mathrm{I}$ NTRATHECAL baclofen (ITB) was approved for the treatment of cerebral spasticity in 1996 and has been increasingly used for treatment of neuromuscular spasticity and dystonia in selected patients with cerebral palsy (CP). 1,26,30,37 Baclofen, a $\gamma$-aminobutyric acid receptor agonist, mitigates hypertonia, and its IT infusion minimizes the systemic side effects observed with enteral administration. 1,3,4,23,28,38 Typically, baclofen is delivered through an indwelling IT catheter inserted at the lumbar spine, with an infusion pump implanted in the abdominal wall. However, patients with severe spastic CP often have comorbid neuromuscular scoliosis, ${ }^{7,28,40}$ which is moderate to severe in $50 \%$ of patients with CP with Gross Motor Function Classification System (GMFCS) Level IV or V. ${ }^{39}$ Both spinal torsion and instrumented spinal fusion constructs complicate IT catheterization at the traditional lumbar insertion site. ${ }^{6,24,28,39}$

Although different techniques to circumvent this anatomical complexity have been described, each is associated with notable limitations. Authors have reported drilling through the fusion mass after localization with fluoroscopy, ${ }^{11}$ using a K-wire to traverse the mass under fluoroscopic guidance, ${ }^{43}$ and inserting catheters at the cervical spine or foramen magnum to avoid entry through the lumbar region altogether. ${ }^{19,29,47}$ However, limitations of these approaches include risks of CSF leakage, catheter dislodgement, and adjacent neural injury. ${ }^{6,10,11,20,24,27,34}$ Given the morbidity associated with perioperative complications of ITB pump placement, many of which require reoperation, advancements in technology and surgical technique are needed to reduce complications and optimize outcomes.

Cone beam CT (CBCT) is an imaging modality that may facilitate IT catheterization in patients with complex anatomy. ${ }^{13} \mathrm{CBCT}$ uses 3D rotational fluoroscopy to create CT-like images, which provide real-time 2D projections for fast visual feedback and 3D reconstructions for detailed volumetric imaging. CBCT may be used to facilitate spinal catheterization in patients undergoing ITB placement; this multimodality approach permits imageguided entry at the lumbar spine below the conus medullaris, improves navigation around spinal instrumentation, and avoids the larger operative exposure required when drilling through the fusion mass. To our knowledge, this is the first description of a series of patients with CP undergoing ITB placement where IT catheterization was facilitated with CBCT image guidance.

\section{Methods}

This case series examined patients who underwent ITB catheterization under CBCT guidance between November 2012 and June 2014. The study was performed after IRB approval was obtained from Boston Children's Hospital. Patients were included if they met the following criteria: 1) presented with spasticity and/or dystonia secondary to $\mathrm{CP} ; 2$ ) had previously undergone thoracolumbar spinal fusion with instrumentation; 3) had a follow-up $\geq 12$ months; and 4) had ITB catheterization and pump implementation performed by the study authors using this multimodality approach. The degree of each patient's deformity was measured by the apical vertebral rotation method. ${ }^{5}$ Images were independently reviewed by 2 authors (F.C.R. and H.H.D.), and discrepancies were resolved by consensus.

\section{Image-Guided Catheterization}

In the interventional radiology (IR) suite, general anesthesia was induced. The patient was positioned prone, prepared, and draped. Chlorhexidine gluconate was used for cutaneous antisepsis before an antimicrobial incise drape (3 MIoban2) was placed over the lumbar spine. Axial images from the CBCT system were acquired and were viewed with iGuide software (Siemens AG), which ideally allows the user to plan the needle trajectory through a lateral insertion site (Fig. 1A-C), thus preserving the midline for the operative incision. Each trajectory plan was individualized according to the initial CBCT images, incorporating the bone thickness and ease of entry, as well as cord location and angle that would avoid catheter kinking.

A percutaneous puncture was performed at an upward angle with image-guided placement of a 14-gauge Bonopty coaxial-sheathed needle (AprioMed), and real-time $2 \mathrm{D}$ projections and $3 \mathrm{D}$ reconstructions provided continuous feedback for navigation during insertion. A 15-gauge Bonopty biopsy drill (AprioMed) was passed through the sheath to provide a canal through the lamina; the drill was used on all patients in this series. A 15-gauge Tuohy needle $(15 \mathrm{~cm})$ was advanced through the thecal sac (Fig. $2 \mathrm{~A}$ and $\mathrm{B})$. Once CSF flow was obtained from the Tuohy needle (Fig. 2C), a15-gauge catheter (Ascenda, Medtronic) was threaded cephalad to the upper thoracic spine using fluoroscopic guidance (Fig. 1D). This was the first of 2 catheters; the IT catheter was later connected to the abdominal catheter.

Because an optimal cephalad ending of the IT catheter is debated, ${ }^{31,46}$ our institutional practice is to place it at the upper thoracic spine due to the theoretical concern of respiratory complications from cervical placement. CSF flow is confirmed from the catheter, and the stylet is replaced to occlude the catheter during patient transport. The IR suites in Boston Children's Hospital lack the capability to perform open surgical procedures, prohibiting concurrent placement of the baclofen pump; therefore, the external catheter tubing was wrapped in sterile dressing, and the patient was transported to the operating room while in the lateral position, with the utmost care to ensure that sterility was maintained and that the catheter was not dislodged.

\section{Surgical Technique}

In the operating room, the patient was typically in the left lateral decubitus position. Both chlorhexidine gluconate and polyvinylpyrrolidone-iodine were used for cutaneous antisepsis. A posterior midline incision was made through the prior fusion surgical incision site, and, if possible, at a site distinct from the percutaneous IT catheter entry site. The spinal catheter was exposed as it entered the lumbar fascia, and a purse-string suture was placed in the fascia around the catheter. After creating an abdominal pocket for the baclofen pump, tunneling of the abdominal catheter was performed. Before connecting the 

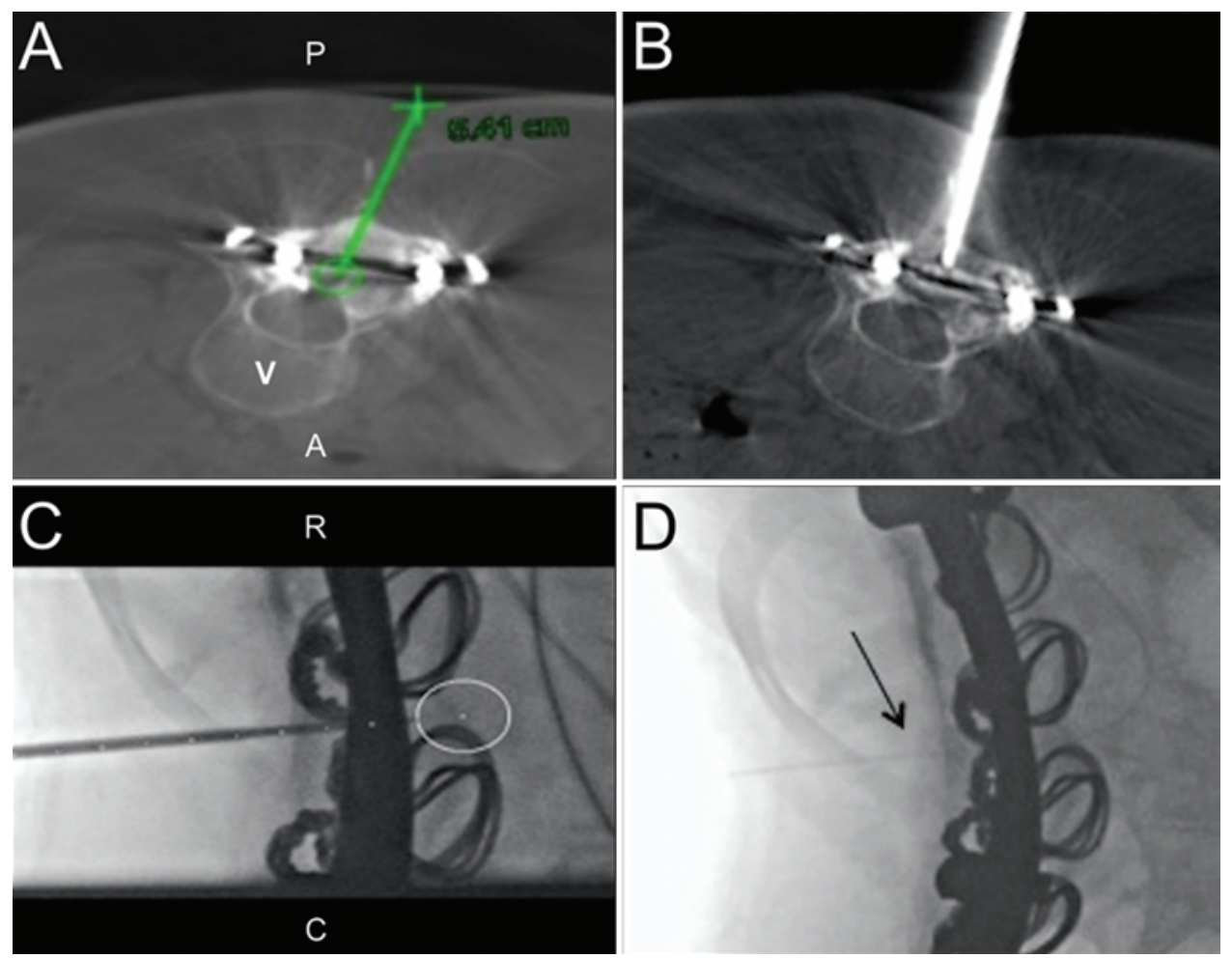

FIG. 1. Interventional imaging. A: Axial CBCT image at L3-4 of user-defined needle trajectory using iGuide software. B: Axial CBCT image with Bonopty penetration sheath in posterior bony fusion correlating with iGuide trajectory. C: Fluoroscopic lateral view of the lumbar spine demonstrating iGuide track overlay correlating with user-defined trajectory. D: Fluoroscopic lateral view of lumbar spine demonstrating IT catheter in position (arrow). $A=$ anterior; $C=$ caudal; $P=$ posterior; $R=$ rostral; $V=$ vertebral body. Figure is available in color online only.

spinal and abdominal catheters at the lumbar incision, the spinal catheter was cut just superficial to the fascia to separate the permanently implanted catheter from the initial percutaneous entry. Once the 2 catheter ends were connected, they were secured to the lumbar fascia with an anchor and nonresorbable sutures (Fig. 2D). CSF flow to the abdominal catheter-pump junction was confirmed before the pump was connected and sutured in place. Finally, the lumbar and abdominal incisions were closed.

\section{Data Collection and Statistical Analysis}

Data were prospectively collected on patient age, sex, year, GMFCS level, surgical indications for ITB pump implantation, comorbidities, extent of spinal fusion, and postoperative complications. Data on insertion site, catheter tip position, IR procedure time, and radiation exposure were collected from radiology images and reports. Outcomes assessed were length of stay, infectious complications, CSF leakage, pump malfunction, reoperations, and follow-up. Descriptive statistics were performed, with parametric or nonparametric testing selected based on whether the measure was normally or non-normally distributed.

\section{Results}

Fifteen consecutive patients with GMFCS Level IV (n $=6)$ or $\mathrm{V}(\mathrm{n}=9) \mathrm{CP}$ are reported (Table 1$)$. The average age was 20.1 years (SD 3.9, range 13-27 years); 7 patients were male and 8 were female. Thirteen of 15 patients reported refractory painful muscle spasms, and 7 of 15 patients had dystonia in addition to spasticity. All patients had undergone instrumented fusion for neuromuscular

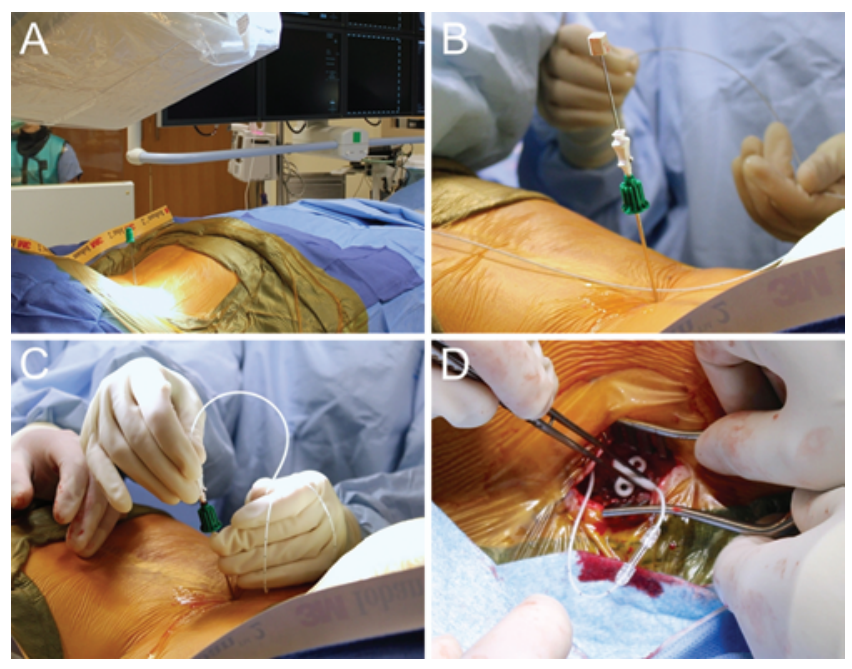

FIG. 2. Catheterization of ITB pump. A: Patients were positioned prone in the IR suite. B: After tunneling through the fusion mass, a Tuohy needle was advanced through a metal sheath into the thecal sac. C: The catheter was threaded cephalad under fluoroscopy. D: In the operating room, a connector joined the IT and abdominal catheters. Images were obtained during a recent case. Figure is available in color online only. 
TABLE 1. Summary of patient data

\begin{tabular}{|c|c|c|c|c|c|c|c|c|c|c|c|}
\hline $\begin{array}{l}\text { Case } \\
\text { No. }\end{array}$ & Type & $\begin{array}{c}\text { Age (yrs), } \\
\text { Sex }\end{array}$ & Dystonia & GMFCS & Deformity* & $\begin{array}{l}\text { Fusion } \\
\text { Level }\end{array}$ & $\begin{array}{l}\text { Cath Entry } \\
\text { Level }\end{array}$ & $\begin{array}{l}\text { IR Time } \\
\text { (hr:min) }\end{array}$ & $\begin{array}{l}\text { Radiation } \\
\text { Dose (Gy) }\end{array}$ & $\begin{array}{c}\text { FU } \\
(\mathrm{mos})\end{array}$ & Complication \\
\hline 1 & Initial & $18, M$ & Yes & V & 3 & T1-S & L3-4 & $2: 43$ & NA & 20 & \\
\hline 2 & Initial & $17, \mathrm{~F}$ & No & V & 3 & T1-S & L5-S1 & 1:14 & NA & 26 & \\
\hline 3 & Initial & $16, F$ & Yes & V & 1 & T1-S & L4-5 & $0: 54$ & 422 & 27 & \\
\hline 4 & Initial & $13, F$ & Yes & V & 2 & T2-S & L5-S1 & $0: 34$ & NA & 29 & \\
\hline 5 & Initial & $22, \mathrm{M}$ & Yes & IV & 0 & T2-S & L5-S1 & $0: 21$ & NA & 30 & P. aeruginosa; explantation \\
\hline 6 & Initial & $13, M$ & No & V & 2 & T2-S & L5-S1 & $0: 27$ & NA & 32 & \\
\hline 7 & Initial & $24, \mathrm{M}$ & No & V & 1 & T2-S & L5-S1 & $0: 19$ & NA & 33 & \\
\hline 8 & Initial & $21, F$ & No & IV & 1 & T1-S & L5-S1 & $0: 42$ & NA & 34 & \\
\hline 9 & Initial & $23, \mathrm{M}$ & No & V & 2 & T2-S & L4-5 & $0: 47$ & NA & 38 & \\
\hline 10 & Revision & $21, F$ & Yes & V & 3 & T2-S & L3-4 & $0: 25$ & 234 & 18 & \\
\hline 11 & Revision & $21, F$ & No & IV & 2 & T2-S & L4-5 & $0: 27$ & NA & 18 & \\
\hline 12 & Revision & $21, M$ & Yes & IV & 2 & T2-S & L4-5 & $0: 57$ & 400 & 21 & \\
\hline 13 & Revision & $27, \mathrm{~F}$ & No & IV & 2 & T2-S & L5-S1 & $0: 16$ & NA & 22 & \\
\hline 14 & Revision & $20, F$ & No & IV & 2 & T1-S & L4-5 & $0: 42$ & 582 & 25 & \\
\hline 15 & Revision & $25, M$ & Yes & V & 4 & T2-S & L5-5 & 1:02 & 1226 & 26 & \\
\hline
\end{tabular}

Cath = catheter; FU = follow-up; NA = not acquired.

* The deformity scale was based on apical vertebral rotation on radiograph. ${ }^{5}$ Images were independently reviewed by 2 authors and discrepancies were resolved by consensus.

scoliosis, with all of the fusions extending from the upper thoracic spine to the sacrum. Nine patients underwent initial catheter and pump placement, and 6 underwent catheter replacement due to index catheter failure. None of the patients for the initial insertion received a baclofen test dose prior to the current procedure, given the expected difficulty with IT administration. The etiologies of the catheter malfunctions for the 6 patients who underwent revision were obstruction $(n=3)$, epidural location $(n=2)$, and suspected microleak $(n=1)$. As is typical of patients with complex $\mathrm{CP}$, most had comorbidities. Six patients had a diagnosis of epilepsy requiring medication. Primary nutritional support was provided via gastrostomy in 8 patients, gastrostomy/jejunostomy in 3 , and by mouth in 4.

The procedure was technically successful, with accurate spinal catheter placement in all patients, and the percutaneous catheterization was not aborted in any cases. The mean IR procedure length was 47 minutes (median 42 , range $16-163$ minutes). For the 5 patients with radiation exposure data available, the mean exposure was 572.8 Gy (median 422, range 234-1226 Gy). The estimated blood loss was minimal in all cases. The median length of stay was 4 days (IQR 3-5 days).

The sole immediate perioperative complication was a urinary tract infection. With a mean follow-up of 25.8 months (median 26, range 18-38 months), all patients and/ or caregivers reported improvement in spasticity and/or dystonia. Additionally, no catheter disconnection, catheter dislodgment, or CSF leakage was reported. However, 1 late infection due to Pseudomonas aeruginosa occurred at 4 months. The same organism grew from the patient's urinary cultures, and recurrent cystitis was the attributed source. The patient required pump explantation and completed antibiotic treatment. The patient subsequently underwent successful reimplantation with 9 months of follow-up.

\section{Discussion}

Intrathecal baclofen for patients with $\mathrm{CP}$ safely and effectively reduces spasticity, pain, and dystonia; in addition, it confers superior functional abilities and results in improved management by caregivers. ${ }^{1,2,9-12,21,25,33,36,43,48}$ However, many patients who require baclofen present with concomitant scoliosis; their spinal torsion, or fusion mass and instrumentation, further increases the challenge of device implantation.,4,620,24,27,34,35,41,42 Moreover, procedural complications decrease the cost-benefit ratio of intervention..$^{11,27,28,43}$ Significant potential postoperative complications include CSF leakage, wound dehiscence, catheter disconnection or dislodgment, and surgical site infection - the latter of which may lead to meningitis and necessitate explantation. ${ }^{2,9,11,17,20,22,24,27,34,36}$

Difficulty entering the spinal canal has been reported in patients with scoliosis who have had surgical correction and lumbar fusions, specifically iatrogenic damage to the catheter, incidental durotomies, CSF leakage, and failure of access. ${ }^{29,32,44}$ Several strategies have been described to facilitate IT catheterization in this setting..$^{39}$ The most common approach involves drilling through the lumbar fusion mass with a high-speed bur. However, a larger open dissection for exploration of the fusion mass may be required.$^{13}$ Additionally, this approach increases the risk of CSF leak and may be associated with longer operative time and increased blood loss. ${ }^{11,43}$ Others have used a Kwire to traverse the mass under fluoroscopic guidance; although tactile feedback can inform entry into the spinal canal, it is difficult to know if or when the K-wire penetrates the dura. ${ }^{43}$ To avoid entry through the lumbar region, 
catheters may be inserted at the cervical spine or foramen magnum. ${ }^{19,29,47}$ However, data on risk of infection and catheter migration with a cervical approach are limited, ${ }^{47}$ and there is the low but real risk of spinal cord injury with entry above the conus medullaris.

Image guidance with CBCT can facilitate ITB implantation when IT catheterization is expected to be technically challenging. To our knowledge, this is the first series to report the use of CBCT during baclofen pump implantation in patients with thoracolumbar scoliosis and previous spinal fusion. In a case report published in 2013, Candler et al. noted the utility of CBCT for successful implantation of an IT morphine pump in an octogenarian with a prior lumbar fusion. ${ }^{13}$ Their success demonstrates the potential of CBCT use in patients with instrumented spinal fusion.

Imaging with CBCT had several advantages in this setting, and all patients had accurate spinal catheter placement. After images are acquired, digital software generates $2 \mathrm{D}$ and 3D projections with submillimeter spatial resolution, providing immediate visual feedback to assist navigation. ${ }^{15}$ A trajectory can be delineated to circumvent spinal instrumentation. Throughout the procedure, fluoroscopy can confirm needle location, and CBCT reconstructions allow for image guidance in the axial plane..$^{6,24}$, 28,39 Using CBCT imaging, a biopsy drill is advanced through the sheath placed under CT guidance to traverse the fusion mass; the smaller diameter of a bone biopsy drill may reduce the risk of CSF leakage, compared with the larger opening from drilling. ${ }^{29,43,47}$ Additionally, lumbar catheterization minimizes the risk of neural injury.

Although frameless stereotaxy is another tool for spinal navigation, optimal software registration may require exposure of vertebral anatomy. In contrast, simultaneous availability of CBCT and high-quality fluoroscopy in the IR suite provides a distinct advantage compared with the operating room, by allowing noninvasive correspondence with precise visualization of the patient's anatomy.

At our institution, this multimodality procedure occurs in 2 locations: the IR suite and the operating room. Therefore, patient transport merits further elaboration. During transport, anesthesia is maintained, the patient's catheter is contained in sterile wrapping, the patient is repositioned upon arrival to the operating room, and then the second part of the procedure is performed. Although there is the theoretical risk of catheter dislodgement or contamination during transport, we have demonstrated that intraoperative relocation is safe, with no resultant complications in this series. Nonetheless, modifications in the technical approach could be made according to institutional facilities and resources. For example, if open procedures were possible in the IR suite, the external end of the Ascenda catheter could be coiled subcutaneously before transport of the patient to the operating room to avoid its external location during transition. Alternatively, at institutions where there is a hybrid operating room equipped with CBCT, patient transport would not be required.

Postoperative infectious complications are common in patients with $\mathrm{CP}$, particularly due to poor nutritional status; additionally, limited patient mobility increases the risk of surgical site infections and decubitus ulcers. ${ }^{14,16}$ Recent studies reported a 10\%-20\% incidence of infec- tion following ITB catheterization, ${ }^{8,22}$ which compares favorably with the $6.7 \%$ infection rate in this series. ${ }^{43}$ The only complication that required reoperation was a pump infection due to Pseudomonas aeruginosa, attributed to systemic dissemination from recurrent urinary tract infections. Many patients with $\mathrm{CP}$ have neurogenic vesicourethral dysfunction, causing reduced bladder capacity, detrusor hyperactivity, and greater postvoid residual, which can instigate urinary tract infections..$^{18,45}$

There are also important limitations to this study. This series is from a single institution and reflects inherent selection bias of the population treated at our institution. All patients with $\mathrm{CP}$ with spasticity and prior instrumented thoracolumbar fusion recently treated at our institution have undergone CBCT-guided ITB catheter insertion. However, outcomes could not be directly compared with historical outcomes from other procedural methods (such as drilling through the lumbar fusion mass) due to inadequate records. Moreover, larger studies of patients undergoing CBCT-guided catheterization at multiple centers would further elucidate the safety, morbidity, and effectiveness of this multimodality approach. Nonetheless, CBCT image guidance for ITB pump catheterization is another approach in the armamentarium of surgeons and interventional radiologists for IT catheterization in patients with scoliosis or instrumented spinal fusion.

\section{Conclusions}

Cone beam CT allowed for image guidance during IT catheterization in patients with spasticity or mixed spasticity and dystonia from CP and prior instrumented thoracolumbar fusion. The multimodality approach resulted in accurate ITB pump implantation, with low periprocedural morbidity. This technique is another potential approach for patients with complex lumbar spine anatomy.

\section{References}

1. Albright AL, Barron WB, Fasick MP, Polinko P, Janosky $\mathrm{J}$ : Continuous intrathecal baclofen infusion for spasticity of cerebral origin. JAMA 270:2475-2477, 1993

2. Albright AL, Ferson SS: Intrathecal baclofen therapy in children. Neurosurg Focus 21(2):e3, 2006

3. Albright AL, Gilmartin R, Swift D, Krach LE, Ivanhoe CB, McLaughlin JF: Long-term intrathecal baclofen therapy for severe spasticity of cerebral origin. J Neurosurg 98:291295, 2003

4. Albright AL, Turner M, Pattisapu JV: Best-practice surgical techniques for intrathecal baclofen therapy. J Neurosurg 104 (4 Suppl):233-239, 2006

5. Anitha H, Prabhu GK: Identification of apical vertebra for grading of idiopathic scoliosis using image processing. J Digit Imaging 25:155-161, 2012

6. Awaad Y, Rizk T, Siddiqui I, Roosen N, McIntosh K, Waines GM: Complications of intrathecal baclofen pump: prevention and cure. ISRN Neurol 2012:575168, 2012

7. Balmer GA, MacEwen GD: The incidence and treatment of scoliosis in cerebral palsy. J Bone Joint Surg Br 52:134137, 1970

8. Bayhan IA, Sees JP, Nishnianidze T, Rogers KJ, Miller F: Infection as a complication of intrathecal baclofen treatment in children with cerebral palsy. J Pediatr Orthop 36:305-309, 2016

9. Berman CM, Eppinger MA, Mazzola CA: Understanding the 
reasons for delayed referral for intrathecal baclofen therapy in pediatric patients with severe spasticity. Childs Nerv Syst 31:405-413, 2015

10. Borowski A, Littleton AG, Borkhuu B, Presedo A, Shah S, Dabney KW, et al: Complications of intrathecal baclofen pump therapy in pediatric patients. J Pediatr Orthop 30:7681,2010

11. Borowski A, Shah SA, Littleton AG, Dabney KW, Miller F: Baclofen pump implantation and spinal fusion in children: techniques and complications. Spine (Phila Pa 1976) 33:1995-2000, 2008

12. Brennan PM, Whittle IR: Intrathecal baclofen therapy for neurological disorders: a sound knowledge base but many challenges remain. Br J Neurosurg 22:508-519, 2008

13. Candler SA, Osborne MD, Derr MJ, Nottmeier EW: Placement of an intrathecal catheter through a bony fusion mass using 3D image guidance: a case report. Clin J Pain 29:e30e32, 2013

14. Colver A, Fairhurst C, Pharoah PO: Cerebral palsy. Lancet 383:1240-1249, 2014

15. Daly MJ, Siewerdsen JH, Moseley DJ, Jaffray DA, Irish JC: Intraoperative cone-beam CT for guidance of head and neck surgery: Assessment of dose and image quality using a Carm prototype. Med Phys 33:3767-3780, 2006

16. Dhiman N, Chi A, Pawlik TM, Efron DT, Haut ER, Schneider EB, et al: Increased complications after appendectomy in patients with cerebral palsy: are special needs patients at risk for disparities in outcomes? Surgery 154:479-485, 2013

17. Dickey MP, Rice M, Kinnett DG, Lambert R, Donauer S, Gerber MA, et al: Infectious complications of intrathecal baclofen pump devices in a pediatric population. Pediatr Infect Dis J 32:715-722, 2013

18. Drigo P, Seren F, Artibani W, Laverda AM, Battistella PA, Zacchello G: Neurogenic vesico-urethral dysfunction in children with cerebral palsy. Ital J Neurol Sci 9:151-154, 1988

19. Dziurzynski K, McLeish D, Ward M, Iskandar BJ: Placement of baclofen pumps through the foramen magnum and upper cervical spine. Childs Nerv Syst 22:270-273, 2006

20. Fjelstad AB, Hommelstad J, Sorteberg A: Infections related to intrathecal baclofen therapy in children and adults: frequency and risk factors. J Neurosurg Pediatr 4:487-493, 2009

21. Furr-Stimming E, Boyle AM, Schiess MC: Spasticity and intrathecal baclofen. Semin Neurol 34:591-596, 2014

22. Ghosh D, Mainali G, Khera J, Luciano M: Complications of intrathecal baclofen pumps in children: experience from a tertiary care center. Pediatr Neurosurg 49:138-144, 2013

23. Gilmartin R, Bruce D, Storrs BB, Abbott R, Krach L, Ward J, et al: Intrathecal baclofen for management of spastic cerebral palsy: multicenter trial. J Child Neurol 15:71-77, 2000

24. Haranhalli N, Anand D, Wisoff JH, Harter DH, Weiner HL, Blate M, et al: Intrathecal baclofen therapy: complication avoidance and management. Childs Nerv Syst 27:421-427, 2011

25. Hoving MA, van Raak EP, Spincemaille GH, Palmans LJ, Becher JG, Vles JS: Efficacy of intrathecal baclofen therapy in children with intractable spastic cerebral palsy: a randomised controlled trial. Eur J Paediatr Neurol 13:240246, 2009

26. Hoving MA, van Raak EP, Spincemaille GH, Palmans LJ, Sleypen FA, Vles JS: Intrathecal baclofen in children with spastic cerebral palsy: a double-blind, randomized, placebocontrolled, dose-finding study. Dev Med Child Neurol 49:654-659, 2007

27. Kolaski K, Logan LR: A review of the complications of intrathecal baclofen in patients with cerebral palsy. NeuroRehabilitation 22:383-395, 2007
28. Koop SE: Scoliosis in cerebral palsy. Dev Med Child Neurol 51 (4 Suppl 4):92-98, 2009

29. Liu JK, Walker ML: Posterior cervical approach for intrathecal baclofen pump insertion in children with previous spinal fusions. Technical note. J Neurosurg 102 (1 Suppl):119-122, 2005

30. Martínez JA, Pinsker MO, Arango GJ, Garcia X, Oscar AE, Furlanetti L, et al: Neurosurgical treatment for dystonia: long-term outcome in a case series of 80 patients. Clin Neurol Neurosurg 123:191-198, 2014

31. McCall TD, MacDonald JD: Cervical catheter tip placement for intrathecal baclofen administration. Neurosurgery 59:634-640, 2006

32. Miracle AC, Fox MA, Ayyangar RN, Vyas A, Mukherji SK, Quint DJ: Imaging evaluation of intrathecal baclofen pumpcatheter systems. AJNR Am J Neuroradiol 32:1158-1164, 2011

33. Morota N, Kubota M, Nemoto A, Katayama Y: [Intrathecal baclofen treatment for spasticity in childhood. initial report of long-term follow up in Japan.] No To Hattatsu 46:179186, 2014 (Jpn)

34. Motta F, Antonello CE: Analysis of complications in 430 consecutive pediatric patients treated with intrathecal baclofen therapy: 14-year experience. J Neurosurg Pediatr 13:301-306, 2014

35. Murphy NA, Irwin MC, Hoff C: Intrathecal baclofen therapy in children with cerebral palsy: efficacy and complications. Arch Phys Med Rehabil 83:1721-1725, 2002

36. Overgård TM, Kjærsgaard-Hansen L, Søe M, Illum NO: Positive experience with intrathecal baclofen treatment in children with severe cerebral palsy. Dan Med J 62:A4999, 2015

37. Penn RD, Kroin JS: Continuous intrathecal baclofen for severe spasticity. Lancet 2:125-127, 1985

38. Penn RD, Kroin JS: Intrathecal baclofen alleviates spinal cord spasticity. Lancet 1:1078, 1984

39. Persson-Bunke M, Hägglund G, Lauge-Pedersen H, Wagner P, Westbom L: Scoliosis in a total population of children with cerebral palsy. Spine (Phila Pa 1976) 37:E708-E713, 2012

40. Saito N, Ebara S, Ohotsuka K, Kumeta H, Takaoka K: Natural history of scoliosis in spastic cerebral palsy. Lancet 351:1687-1692, 1998

41. Sampson FC, Hayward A, Evans G, Morton R, Collett B: Functional benefits and cost/benefit analysis of continuous intrathecal baclofen infusion for the management of severe spasticity. J Neurosurg 96:1052-1057, 2002

42. Saulino M, Guillemette S, Leier J, Hinnenthal J: Medical cost impact of intrathecal baclofen therapy for severe spasticity. Neuromodulation 18:141-149, 2015

43. Scannell B, Yaszay B: Scoliosis, spinal fusion, and intrathecal baclofen pump implantation. Phys Med Rehabil Clin N Am 26:79-88, 2015

44. Schapiro A, Racadio J, Kinnett D, Maugans T: Combined $\mathrm{C}$-arm fluoroscopy and $\mathrm{C}$-arm cone beam computed tomography for the evaluation of patients with possible intrathecal baclofen delivery system malfunctions. Neurosurgery 69 (1 Suppl Operative):ons27-ons33, 2011

45. Silva JA, Alvares RA, Barboza AL, Monteiro RT: Lower urinary tract dysfunction in children with cerebral palsy. Neurourol Urodyn 28:959-963, 2009

46. Sivakumar G, Yap Y, Tsegaye M, Vloeberghs M: Intrathecal baclofen therapy for spasticity of cerebral origin - does the position of the intrathecal catheter matter? Childs Nerv Syst 26:1097-1102, 2010

47. Ughratdar I, Muquit S, Ingale H, Moussa A, Ammar A, Vloeberghs M: Cervical implantation of intrathecal baclofen pump catheter in children with severe scoliosis. J Neurosurg Pediatr 10:34-38, 2012

48. Ward A, Hayden S, Dexter M, Scheinberg A: Continuous 
intrathecal baclofen for children with spasticity and/or dystonia: Goal attainment and complications associated with treatment. J Paediatr Child Health 45:720-726, 2009

\section{Disclosures}

The authors have no conflicts of interest related to any commercial entity listed in this paper. In the past Dr. Berde has received research support from Purdue Pharma and WEX Pharmaceuticals and has served as a consultant for Cubist Pharmaceuticals and CVS. Dr. Berde's primary research area concerns the development of new local anesthetics. He and his colleagues have issued patents, and Boston Children's Hospital has licensed one of these local anesthetics (neosaxitoxin) to a pharmaceutical company for clinical development. Should neosaxitoxin prove successful in clinical trials, Dr. Berde, his colleagues, and Boston Children's Hospital could potentially receive royalties. This local anesthetic would be used for postoperative analgesia, and no use by intrathecal pumps or in any manner related to the current article is envisioned.

\section{Author Contributions}

Conception and design: Robinson, Berde, Padua. Acquisition of data: Robinson, Robertson, Dasenbrock, O’Brien, Padua. Analysis and interpretation of data: Robinson, Dasenbrock, O'Brien, Berde, Padua. Drafting the article: Robertson, Dasenbrock, O'Brien. Critically revising the article: all authors. Reviewed submitted version of manuscript: Robinson, Robertson, Dasenbrock. Approved the final version of the manuscript on behalf of all authors: Robinson. Statistical analysis: Robinson. Administrative/technical/material support: Robinson. Study supervision: Robinson.

\section{Supplemental Information}

\section{Previous Presentations}

This abstract was presented in poster form at the 2015 Congress of Neurological Surgeons Annual Meeting, New Orleans, LA, September 26-30, 2015.

\section{Correspondence}

Shenandoah Robinson, Department of Pediatric Neurosurgery, Johns Hopkins University School of Medicine, Phipps 556, $600 \mathrm{~N}$ Wolfe St., Baltimore, MD 21287. email: srobin81@jhmi.edu. 